\title{
Environmental biotechnology and engineering: two convergent areas to provide real solutions for a growing world
}

\author{
Roberto Candal ${ }^{1,2}$ - Gustavo A. Curutchet ${ }^{1,2} \cdot$ Lilian Domínguez-Montero $^{3} \cdot$ Hervé Macarie $^{4}$. \\ Héctor M. Poggi-Varaldo ${ }^{3}$ Isabel Sastre-Conde ${ }^{5} \cdot$ Susana C. Vázquez ${ }^{6,7}$
}

Received: 12 June 2018 / Accepted: 20 June 2018 / Published online: 27 June 2018

(C) Springer-Verlag GmbH Germany, part of Springer Nature 2018

World population is growing fast, in parallel with the use of natural resources and waste generation. Therefore, it is mandatory to take actions immediately to preserve the environment and the health and living conditions of the people. In this sense, biotechnology and engineering are key tools to provide solutions to a world with serious environmental problems.

The advances in both Biotechnology and Engineering are usually covered by international meetings that typically dedicate only one or two sessions to environmental applications. However, the synergistic interaction of environmental biotechnology and environmental engineering has an enormous potential for the generation of important contributions to a more sustainable development of the present society. These contributions will undoubtedly lead to the improvement of the

Responsible editor: Philippe Garrigues

Susana C. Vázquez

svazquez@ffyb.uba.ar

Roberto Candal

rjcandal@gmail.com

Gustavo A. Curutchet

gcurut@gmail.com

Lilian Domínguez-Montero

lilian.d.montero@gmail.com

Hervé Macarie

herve.macarie@ird.fr

Héctor M. Poggi-Varaldo

r4cepe@yahoo.com

Isabel Sastre-Conde

isabelsastre2003@yahoo.es

1 Escuela de Ciencia y Tecnología e Instituto de Investigación e Ingeniería Ambiental, Universidad Nacional de San Martín (UNSAM), 25 de Mayo y Francia, San Martin, Argentina life quality of the people and preserve the natural resources for the future generations. To help achieve this goal, the scientific community must interact in a multidisciplinary way and join efforts to come up with new ideas and thus, there was a need for an international meeting dedicated to both disciplines, with a strong vocation to share scientific and technological knowledge and promote research networking. The International Symposium on Environmental Biotechnology and Engineering (ISEBE) was conceived to present the advances in both convergent disciplines, where researches from all over the world could find a friendly ambience to share novel ideas, doubts, problems, and solutions related to these important areas of knowledge.

In this way, a series of events was developed, that began in Mexico in 2004 with the First International Meeting on

2 CONICET, Consejo Nacional de Investigaciones Científicas y Técnicas, Godoy Cruz, 2290 Buenos Aires, Argentina

3 Environmental Biotechnology and Renewable Energies R\&D, Group, Dept. Biotechnology and Bioengineering, Cinvestav-IPN, Av. Instituto Politécnico Nacional 2508, Col. San Pedro Zacatenco, Delegación Gustavo A. Madero, C. P. 07360, 14-740, 07000 Mexico City, Mexico

4 Aix Marseille Univ, Univ Avignon, CNRS, IRD, IMBE, Marseille, France

5 SEMILLA-INAGEA, Calle Babieca n², 07198 Son Ferriol (Palma), Balearic Islands, Spain

6 Facultad de Farmacia y Bioquímica, Cátedra de Biotecnología, Universidad de Buenos Aires, Junín 956, 1113 Buenos Aires, Argentina

Instituto de Nanobiotecnología (NANOBIOTEC), Universidad de Buenos Aires - CONICET, Junín 956, 1113 Buenos Aires, Argentina 
Environmental Biotechnology and Engineering (IMEBE). This meeting was followed by the second and third IMEBE held in Mexico and Palma de Mallorca (Spain) in 2006 and 2008 , respectively. Due to the exponential growth of interest in this series of meetings, in 2014, the 4th edition (4ISEBE) was carried out again in Mexico, now with the status of Symposium. In this opportunity, the fifth edition of the ISEBE was celebrated in San Martín city, Buenos Aires, Argentina, as an attempt to foster the participation of researchers from the south hemisphere, which concentrates most of the developing countries and the most serious environmental problems. The great impact of 5ISEBE is clearly seen in the 283 contributions sent by scientists from Latin American countries such as Argentina, Brazil, Chile, Colombia, Ecuador, Mexico, Peru, and Uruguay. European countries (Belgium, France, Italy, Slovak Republic, Spain) and Canada, and African countries like Algeria, Burkina Faso, and South Africa were also represented. This special issue of Environmental Science and Pollution Research has 19 articles elaborated from these contributions, representing the research areas Degradation of recalcitrant pollutants, Improvement of biotechnological processes, Fate of pollutants in different environments, Advanced treatments for contaminants and disinfection, and Thermal valorization of wastes, eco-pesticides, and miscellaneous.

Below, there is a succinct list of the articles enclosed in this special issue, classified by research areas:

Degradation of recalcitrant pollutants

1. Monitoring and modeling 4-chlorophenol biodegradation kinetics by phenol-acclimated activated sludge by using open respirometry.

2. Experimental and kinetic study for lead removal via photosynthetic consortia using genetic algorithms to parameter estimation.

3. Organophosphorus pesticide mixture removal from environmental matrices by a soil Streptomyces mixed culture.

Improvement of biotechnological processes

1. The effect of substrate/inoculum ratio on the kinetics of methane production in swine wastewater anaerobic digestion.

2. Strategy to identify the causes and to solve a sludge granulation problem in methanogenic reactors: application to a full-scale plant treating cheese wastewater.

3. Evaluation of color temperatures in the cultivation of Dunaliella salina and Nannochloropsis oculata in the production of lipids and carbohydrates.

4. Predicting attenuation of solar radiation (UV-B, UV-A, and PAR) in waste stabilization ponds under Sahelian climatic conditions.
Fate of pollutants in different environments

1. The pesticide chlordecone is trapped in the tortuous mesoporosity of allophane clays.

2. Non-essential element concentrations in brown grain rice: assessment by advanced data mining techniques.

3. Effects of pollution and bioleaching process on the mineral composition and texture of contaminated sediments of the Reconquista River, Argentina.

Advanced treatments for contaminants and disinfection

1. New semi-pilot scale reactor to study the photocatalytic inactivation of phages contained in aerosol.

2. Advanced oxidation of commercial herbicides mixture: experimental design and phytotoxicity evaluation.

3. Study of plasma off-gas treatment from spent ion exchange resin pyrolysis.

4. Devitalization of pathogens in stored pig slurry and potential risk related to its application to agricultural soil.

Thermal valorization of wastes, eco-pesticides, and miscellaneous

1. Combustion of pistachio shell: physicochemical characterization and evaluation of kinetic parameters.

2. A bionanohybrid ZnAl-NAD ecological pesticide as treatment of soft rot disease on potato (Solanum tuberosum L.).

3. Novel insights in biopurification system for dissipation of a pesticide mixture in repeated applications.

4. Improved strength and durability of concrete through metabolic activity of ureolytic bacteria.

5. Proteolytic extracts of three Bromeliaceae species as ecocompatible tools for leather industry.

We want to acknowledge all authors of the contributions presented in the 5ISEBE and express our gratitude to 3iAUNSAM, Comisión de Investigaciones de la Provincia de Buenos Aires (CIC), Consejo Nacional de Investigaciones Científicas y Técnicas (CONICET), French National Research Institute for Sustainable Development (IRD), and Asociación de Biotecnología, Ingeniería Ambiental y Energías Renovables (ABIAER) for supporting the meeting. We are also very grateful to the editor-in-chief, Professor Dr. Phillipe Garrigues, and his team of Associate Editors and Reviewers for their excellent work in the selection, evaluation, and management of articles from 5ISEBE submitted to the journal Environmental Science and Pollution Research.

We invite the readership to consult the articles published in the present issue of Environmental Science and Pollution Research, along with those published in the book entitled Environmental Biotechnology and Engineering Advances 2016 (Candal et al. 2017) to keep updated in the efforts that 
we should still make to improve our environment and quality of life. We look forward to meeting all of you along with a stream of new participants in the next 6th ISEBE in 2018, Ciudad Obregón, Sonora, Mexico (www.itson.mx/6isebe).

\section{Reference}

Candal R, Curutchet G, Domínguez-Montero L, Macarie H, PoggiVaraldo H, Vázquez S, Sastre I. (eds.) (2017) Environmental biotechnology and engineering: ISEBE advances 2016. Cinvestav, Mexico City, 1030 pages. ISBN 978-607-9023-44-7 (http://www. documentation.ird.fr/hor/fdi:010072565)

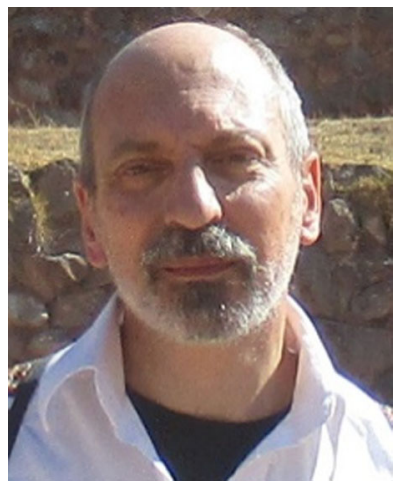

Roberto J. Candal is Associate Professor at the National University of San Martín (UNSAM) and Principal Researcher at the Argentinean National Scientific and Technical Research Council (CONICET). He holds a degree in Chemistry (1988) and a PhD (1995) in Inorganic Chemistry from the University of Buenos Aires (UBA). He is one of the founders and an active member at the Argentinean Society of Environmental Science and Technology, and Secretary of Research at the Environmental Science and Engineering Institute, UNSAM. After his $\mathrm{PhD}$, he worked for three years at the Water Chemistry Science and Engineering Laboratory, University of Wisconsin, WI, USA, at Professor Marc Anderson's group. He has developed research in materials science, advanced oxidation, photocatalysis, and environmental chemistry. His research is focused on new materials for environmental applications, biodegradability of plastics, advanced oxidation for water treatment and coupled processes for wastewater treatment. $\mathrm{He}$ has mentored eight $\mathrm{PhD}$ theses and published more than 80 peerreviewed articles in recognized international journals.

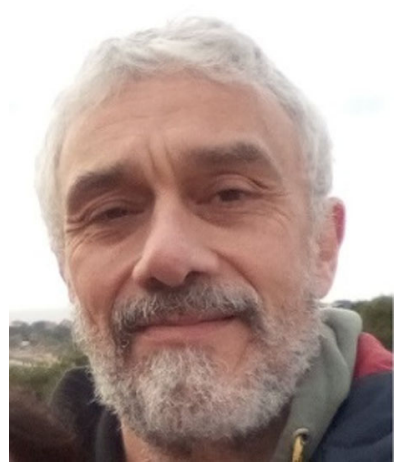

Gustavo A. Curutchet graduated as Biochemist (1990) and holds a PhD (1996) from Universidad Nacional de La Plata, Argentina. $\mathrm{He}$ is a senior researcher at the Argentinian Council for Science and Tecnology (CONICET) and, since 2002 , he is full professor at Universidad Nacional de San Martín, Argentina, where he founded the Laboratory for Treatment of Special Effluents and Wastes. He is a specialist in bioremediation and treatment of industrial wastes and effluents.

He currently leads a team of researchers studying biocatalized redox processes in contaminated environments and its application to bioremediation. Together with researchers from other institutions, he is PI or collaborator in numerous grants and projects. Nowadays, his work is mainly related to the study of the natural mechanisms of attenuation of contamination in heavily polluted urban and semi-urban basins (Reconquista River, Argentina) and develops remediation strategies to treat water, sediments, wastes, and effluents using native microorganisms and coupling bioleaching, bioreduction, biosorption, and other processes. His research projects include social aspects of how pollution and remediation processes impact people living in the precarized neighborhoods near the Reconquista River basin. He is the author of more than 50 peerreviewed articles published in recognized journals and a mentor of several $\mathrm{PhD}$ theses.

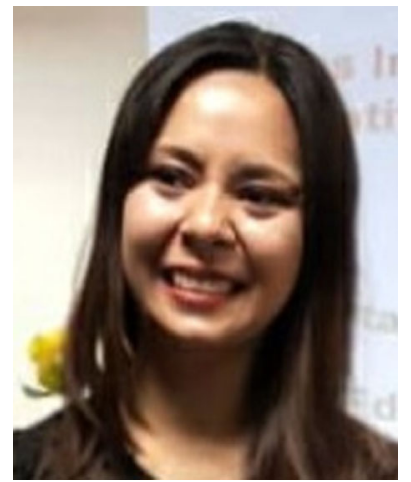

Lilian Domínguez-Montero holds a PhD (2018) on Scientific and Technological Development for the Society from the Centre for Higher Studies and Research (CINVESTAV, IPN), Mexico City, Mexico. She is a member of the Environmental Biotechnology and Renewable Energies R\&D Group (GBAER for its abbreviation in Spanish). She has developed research on the economic, technological, and regulatory aspects of wastewater treatment; multivariate analysis of municipal wastewater treatment plants in Mexico, and on persistent organic pollutants (POPs) and emerging contaminants in wastewaters. She followed the certification course on Quality Management Systems ISO 9001:2008 and on Environmental Management Systems ISO 14001:2004, both granted by the Spanish Association for Standardization and Certification (AENOR for its abbreviation in Spanish), and she obtained a bachelor's degree in industrial chemical engineering from the School of Chemical Engineering and Extractive Industries of the National Polytechnic Institute (IPN). From 2009 to 2012, she was the Research and Development Manager of the transnational company Micro Abrasivos, collaborating with the development of new products and processes on silicon carbide, aluminum oxide, and boron carbide manufacture. She was a member of the organizing committee in different international congresses, including the International Symposium on Environmental Biotechnology and Engineering (ISEBE's series of events), and participated as a workshop speaker and guest speaker at national events on science dissemination. She has published 7 book chapters, 4 full articles in international symposiums and congresses, and 3 articles of science popularization. She is a member of the managing committee of the ABIAER association where she is responsible of the association website management particularly the section with the publications generated during the ISEBEs and other events supported by ABIAER. 


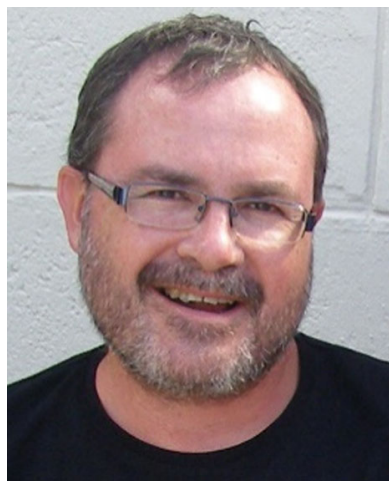

Hervé Macarie is a research officer at the French National Research Institute for Sustainable Development (IRD exORSTOM). In this position since October 1994, he has developed research on the technological and the microbiological aspects (taxonomy and ecology) of the anaerobic treatment of industrial wastewater and he has both an experience at lab and full scale (up to reactors of $20,000 \mathrm{~m}^{3}$ ). One of his main interests has been for the anaerobic degradation of xenobiotic compounds such as terephthalic acid and pentachlorophenol and the development of synchronous anaerobic/aerobic systems to achieve the full mineralization of this last compound. Since 2008, his research has been almost entirely focused on the microbial degradation of chlordecone, an organochlorine insecticide classified as POP that was once used against the banana black weevils and that is now responsible, 24 years after the ban of its utilization, of a health, environmental, economic, and social crisis in the French West Indies islands of Guadeloupe and Martinique. Along his career, he has been successively in position in Canada (postdoctoral fellow, BRI, NRC, 1992-1994), Mexico (visiting Professor, UAM-Iztapalapa, 1995-2000), continental France (Aix Marseille University, 2001-2010), and Martinique (CAEC, 20112014). Since 2015, he is back to Aix Marseille University and IMBE (Mediterranean Institute for Marine and Continental Biodiversity and Ecology) where he pursues his research on the theoretical and experimental aspects of chlordecone degradation with the objective to understand the factors limiting its natural attenuation and the possibility to manipulate them in order to propose a bioremediation process to decontaminate the polluted soils.

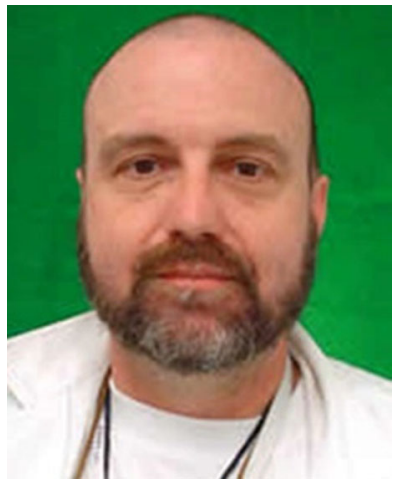

Professor Dr. Héctor M. PoggiVaraldo is a full professor in the Dept. of Biotechnology and Bioengineering at the Centre for Higher Studies and Research (CINVESTAV del IPN) in Mexico City, Mexico. $\mathrm{He}$ is the founder and leader of the Environmental Biotechnology and Renewable Energies R\&D Group (GBAER for its abbreviation in Spanish). He holds a Sc. D. degree in Biotechnology from CINVESTAV del IPN, a M. Sc. Environ. Eng. from the National Autonomous University of Mexico, and a B. Sc. Chem. Eng. from the National University of Uruguay. He has been awarded the Prize to Distinguished Academic Career from the Mexican Polytechnic Institute in 1999. $\mathrm{He}$ has also won two awards to the Best Research Projects from the Mexican Society for the Management of Solid and Hazardous Wastes in 1998. In 2017, Prof. Poggi-Varaldo received the McKee Award for Groundwater Protection, Restoration, and Sustainable Use from the Water Environment Federation, USA. With his students, he has won six international awards to Best Articles in international Battelle Conferences and Symposia (USA, 2007 to 2013) related to biorefinery of wastes and bioelectricity. He has been invited as an expert in soil bioremediation by the French government for advising on the chlordecone contamination and remediation in the French West Indies in 2010. Also, the European Commission invited him in 2011 to perform as a referee for evaluation of megaprojects submitted to the 7th EU Research Framework Program. Furthermore, he is the author of a Mexican Patent on a type of anaerobic fluidized bed reactor as well as a patent application for generation of biohydrogen and methane from organic solid wastes. His research interests are focused on (i) bioenergies and biorefinery of organic wastes, (ii) bioremediation of heavy soils polluted with pesticides, (iii) bioelectricity from effluents, (iv) treatment of toxic and industrial wastewaters, and (v) nanobiotechnology applied to bioelectrochemical devices and bioremediation of soils and aquifers. He is the author of nearly 140 articles in refereed journals indexed in the Web of Science (WOS). He holds the category H24 according to the WOS. Also, he has published more than 40 chapters in books and has been the editor of 10 books, as well as more than 150 full articles in international symposia and congresses.

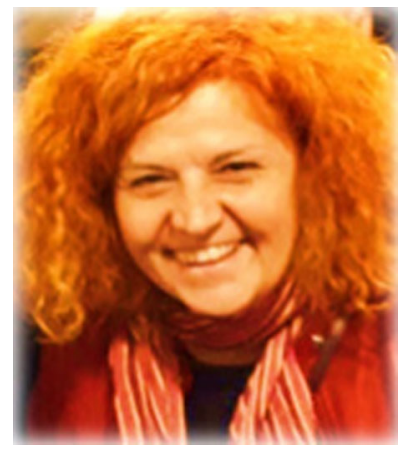

Isabel Sastre Conde qualified in $\mathrm{BSc}$ in Biological Sciences from the Complutense University of Madrid and doctoral degree in Agricultural Chemistry at the Autonomous University of Madrid. She has participated in the frame of the AECI-ANUIES Spanish-Mexican program of reinforcement of Mexican province Universities as a ResearcherProfessor first at the UNACAR (Universidad Autonoma del Carmen), Campeche State and then at UV (Universidad Veracruzana) in Veracruz City. During that period, she started a collaboration with Dr. Poggi's environmental lab at Cinvestav-IPN, Mexico, where she later made three short-term stays while she had a postdoctoral research position at IMIDRA (Instituto Madrileño de Investigación y Desarrollo Rural, Agrario y Alimentario) in Spain. In 2004, she obtained a 5-year researcher position at Conselleria d'Agricultura from Balearic Island (Spain) into the frame of the DOC-INIA program. Since 2006, she got a permanent researcher position at SEMILLA (a semi-public company under the authority of the Agricultural Regional Direction of the Balear Province Government). Currently, she is a permanent researcher of SEMILLA-INAGEA. Her main research interest has been towards the study of the risk of contamination of soils and sediments as well as towards the restoration and remediation of impacted environments. On these aspects, she has participated in numerous projects in collaboration with IMIDRA, within the framework of EIADES program. With researchers from other countries, she was involved in Mexican projects on the impact of the oil industry on coastal lagoon systems, but also on the impact of long-term (100 years) irrigation with raw sewage on agricultural soils. In collaboration with French researchers, she has worked also on the bioremediation of soils contaminated by chlordecone, an organochlorine insecticide used during decades for the control of the populations of banana weevils in French West Indies. Since 2006, her research activity has been focused towards the use of composted organic material as an alternative to the inorganic nitrogen fertilizer presently used 
in important crops of the Balearic Islands (almonds and tomatoes) with the objective to reduce at minimum the risk of aquifer pollution by nitrate. All these research activities have given her a deep knowledge of the soil characteristics under stress situations (natural, agrarian, degraded, and polluted soils). Very recently, she started to participate to projects on soil bioremediation with nanomaterials, the use of soil for a sustainable agriculture, and the role of soil on the risk of invasion by the Xylella fastidiosa bacteria for the agriculture of the Balearic Islands.

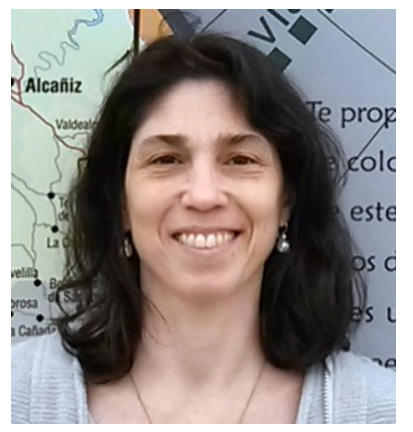

Susana C. Vázquez is a researcher at the Argentinean National Scientific and Technical Research Council (CONICET) and a teaching assistant at the Pharmacy and Biochemistry Faculty at the University of Buenos Aires (UBA). She holds a degree in Biochemistry (1993) and $\mathrm{a} \mathrm{PhD}$ in Biotechnology (2 0000$)$ from the UBA, Argentina. She is an active member at the Agricultural and Environmental Division of the Argentinean Society for Microbiology, where she participates in the organization of courses and meetings. Since 1994 has conducted research on Antarctic microbiology, as a member of the Microbiology Group at the Instituto Antártico Argentino, joining 10 expeditions to Antarctica. After her $\mathrm{PhD}$, she worked for six months with Dr. Balbina Nogales at University of Balearic Islands (postdoctoral fellow, CONICET, 2005) and later she has been 7 times on secondment to the Alfred Wegener Institute, Bremerhaven, Germany, in collaboration with Dr. Elisabeth Helmke and Dr. Stephan Frickenhaus and made three short-term stays at the MPI for Microbiology, Bremen, Germany, as participant of the EU networking project IMCONet (EU FP7 IRSES, action no. 318718). She has developed research on cold enzymes and the isolation of heterotrophic Antarctic bacteria with different metabolic interesting features, partly under agreement with two private companies. Since 2001, her work has been mainly focused on the study of accidental diesel spills and the role of the hydrocarbon-degrading native microbiota on the bioremediation of the contaminated soils at Carlini Station, South Shetland Islands. 